\title{
Challenges and Opportunities in the Operationalization of the Water-Environment- Energy-Food (WE'F) Nexus: Case Study of the Upper Niger Basin and Inner Niger Delta, West Africa
}

\author{
Ousmane Seidou', Fatoumata Maiga', Claudia Ringler², Spela Kalcic ${ }^{3}$, \\ Luca Ferrini ${ }^{4}$
}

${ }^{1}$ University of Ottawa, Department of Civil Engineering, 161 Louis Pasteur, Ottawa (ON) K1N 6N5, Canada

${ }^{2}$ Environment and Production Technology Division, International Food Policy Research Institute, 2033 K Street, NW, Washington, DC 20006-1002, USA

${ }^{3}$ Freelance researcher and consultant, Brilejeva 3, 1117 Ljubljana, Slovenia / Unamontie 8c 22, 00610 Helsinki, Finland

${ }^{4}$ GIZ Office Niger, Avenue de l'Afrique, Porte $N^{\circ} 36$, Niamey, Niger

\begin{abstract}
The ever-increasing demand for water, food, and energy is putting unsustainable pressure on natural resources worldwide, often leading to environmental degradation that, in turn, affect water, food, and energy security. The recognition of the complex interlinkages between multiple sectors has led to the creation of various holistic approaches to environmental decision making such as Integrated Natural Resources Management (INRM), Integrated Water Resources Management (IWRM), Virtual Water (VW), Water Footprint (WF) and lately the Food-EnergyEnvironment-Water nexus (WE2F). All these approaches aim to increase resource use efficiency and promote sustainability by increasing the cooperation between traditionally disjoint sectors, and mainly differ by the number and relative weights of the sectors included in their framework. They also suffer from the same face and the same barriers for implementation, some of which may never be fully overcome. The paper discusses the benefits of adopting a WE2F nexus approach in the Upper Niger Basin (UNB) and the Inner Niger Delta (IND), but also the multiple difficulties associated with its practical implementation. IWRM/WE2F initiatives in the UNB/IND such as the BAMGIRE project piloted by Wetlands International and funded by the Dutch Embassy in Mali to secure livelihoods and biodiversity in a changing environment, is taken as an example of partial success in the use of a nexus approach to watershed management. It was shown there are multiple barriers to the operational implementation of the WE2F. However, while a full understanding of all interlinkage between sectors may never be possible, data collection, scientific research and model development can improve our ability to
\end{abstract}


understand the complex system in which we live, and hence take better decisions

\section{Introduction}

The United Nations expect the world's population to be increasing at least until 2050[1]. The population will peak at 11.2 billion people in 2100 according to the median projection, and the fastest growth will be occurring in Africa. Resource consumption per capita will also be increasing as people in developing countries are inexorably trending towards a western-style lifestyle, which require more energy, more water and has a greater environmental footprint. Rather than increasing, the availability of natural resources are actually decreasing as the result of overexploitation, environmental degradation and climate change. According to the UN International Panel on Resources, 90\% of biodiversity loss and water stress in addition to half of the global greenhouse gas emission are caused by resource extraction and processing[2], despite the fact that the call for sustainability in resource extraction is getting louder and louder in the international discourse. Sustainability was promoted to the centre stage of the global agenda with the Sustainable Development Goals (SDG), put forward by the UN at the United Nations Conference on Sustainable Development in Rio de Janeiro in 2012. A key characteristic of the SDG is that the UN explicitly recognize that 'action in one area will affect outcomes in others, and that development must balance social, economic and environmental sustainability'[3].The need to account for positive and negative interactions between interventions and objectives in different sectors of the economy of the environment is not new, and has led to the creation of various holistic approaches to environmental decision making such as Integrated Natural Resources Management (INRM[4], [5]), Integrated Water Resources Management (IWRM[6]-[8]), Virtual Water (VW[9]-[11]), Water Footprint (WF[12], [13]) and lately various declinations of the Food-Energy-Environment-Water nexus (WE² F[14], [15]).

All these frameworks aim to promote resource management that transcends sectors, disciplines and scales, and the main differences reside in the number and relative weights of disciplines/scales/sectors included. The $\mathrm{WE}^{2} \mathrm{~F}$ nexus focuses on the inter-linkages across three key sectors, namely the water, energy, food sector, and their interlinkages with environmental sustainability (Figure 1).

Given growing natural resource scarcity worldwide, these interlinkages continue to strengthen, making it increasingly unlikely that developments or investments in one of these sectors do not also affect one or more of the other sectors. The whole system is under direct and indirect divers of change such as population growth and climate change. The changes induced by these drives affect sustainability outcomes such as food security and environmental quality. Fig. 2 illustrates the complex linkages, dependencies and trade-offs between food, water and energy, the drivers of change and the environmental services that their provision depends on.Fig. 2. 


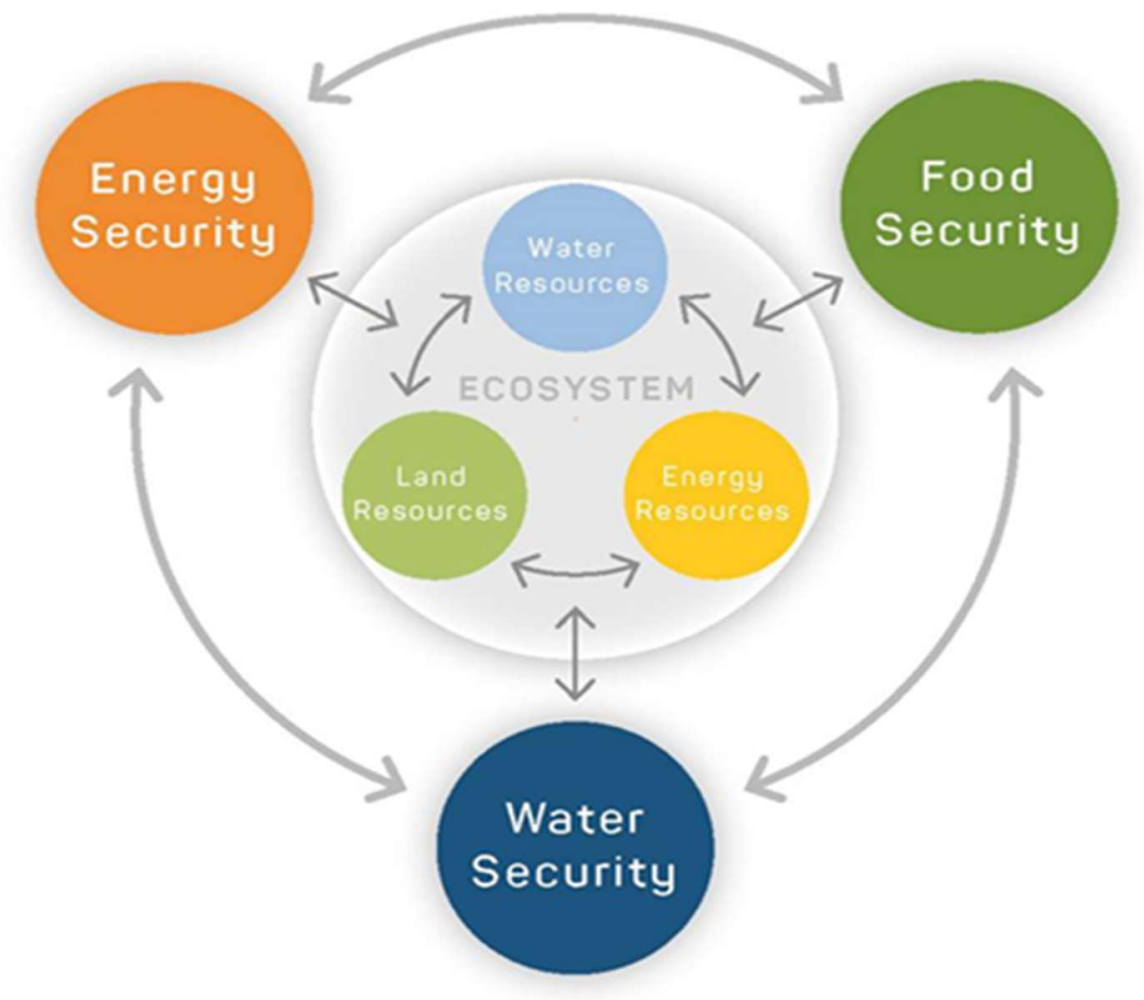

Fig. 1. WE2F diagram ${ }^{15}$

Nexus related frameworks that examine the link between two seemingly disjoint sectors date back to the '80s[16], but one of the earliest explicit references to the water-energyfood nexus can be found in background paper of the Bonn 2011 Conference on Water, Energy and Food Security Nexus[14]. The nexus was introduced as a novel approach that can enhance water, energy and food security by increasing efficiency, reducing trade-offs, building synergies and improving governance across sectors.

However, the ambitious aims of the nexus - the desire to capture multiple interdependencies across major sectors, across disciplines and across scales-could become its downfall[17]. Barriers to the implementation of the $\mathrm{WE}^{2} \mathrm{~F}$ include ambiguity in its definition, the strong assumption that integration (of sectors, disciplines, knowledge and stakeholders) is possible and desirable[18], the complexity of the natural system and the lack of understanding of the interdependencies and connections across the $\mathrm{WE}^{2} \mathrm{~F}$ systems. The operationalisation of the $\mathrm{WE}^{2} \mathrm{Fis}$ also limited by the fact that comprehensive $\mathrm{WE}^{2} \mathrm{~F}$ nexus tool is yet to be developed ${ }^{15}$ : existing tools are either conceptual, qualitative, and large scale, possibly oversimplifying the interactions between sectors, either quantitative and limited in space or number of sectors covered to manage complexity. Additional challenges come from the fact synergies and trade-offs involve monetary and non-monetary values, the mismatch between nexus boundaries and traditional management units, multiple spatial and temporal dimensions, heterogeneous procedures for various nexus dimensions[19]. All the above challenges can be found in the Upper Niger Basin (UNB), where food and energy security are seen as national priorities, but clash their development 
may clash with environmental sustainability already threatened by climate change, desertification and population growth. The UNB drains into the Inner Niger Delta (IND), a wetland of global importance that provides natural resources and livelihoods for over $10 \%$ of Mali's population and $80 \%$ of Mali fish production. The IND also produces food for about $40 \%$ of the country's cattle \{Citation\}. The wetland is known to be extremely sensitive to flood regime in the IND, there is a widespread concern current, and planned dams and irrigation schemes in the IND could lead to a collapse of ecosystems in the IND, making it a perfect case study for a $\mathrm{WE}^{2} \mathrm{~F}$ analysis.

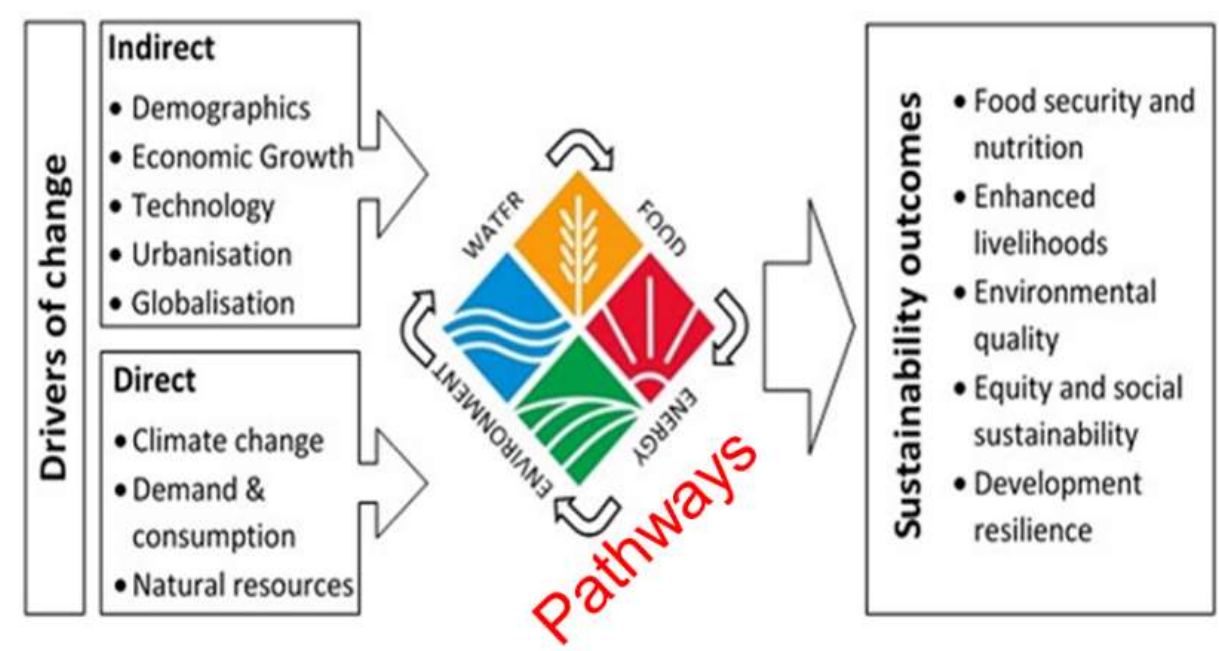

Fig. 2.Dependencies between drivers of change, the $\mathrm{W}^{2} \mathrm{EF}$ and sustainability outcomes. Adapted from [20]

In 2016, the Embassy of the Kingdom of the Netherlands (EKN) in Mali commissioned Wetlands International to implement The BAMGIRE (BAM=Bamako; GIRE=Gestion Intégrée des Ressources en Eau=Integrated Water Management). The aim of the BAMGIRE is to secure livelihoods and biodiversity in a changing climate, and build the capacity in Mali and Guinea on water management with a special focus on sustaining essential ecosystem services in the IND and other upstream wetland ecosystems. While the project title refers to IWRM rather than the $\mathrm{WE}^{2} \mathrm{~F}$, the project simultaneously considered hydropower production, food security, water security and environmental sustainability and hence qualifies as a $\mathrm{W}^{2} \mathrm{EF}$ project. Wetlands International tasked international partnersto support Mali in the development of state of the art knowledge and technical tools that would help.This paper describes the efforts deployed between 2016 and 2020 within the BAMGIRE project to decipher the complex relationships between dam management, irrigation, climate change and ecosystem services in the IND and UNB.

\section{The Upper Niger Basin and Inner Niger Delta}

The Upper Niger Basin (UNB) and the Inner Niger Delta (IND) are part of the Niger River basin (Figure 3), the third longest river in Africa. The Niger River watershed has a total area of 2.262 million $\mathrm{Km}^{2}$ and flows through 10 African countries starting in Guinea, where the river headwater is located, then flows $4100 \mathrm{~km}$ into the Atlantic Ocean in coastal Nigeria. The majority of the river is located in Nigeria, Mali, and Niger with respectively $25.7 \%, 25.5 \%$ and $24.8 \%$ of the total area. Over 1 million people depend on the Niger River 
resources. The Inner Niger Delta is a large floodplain located on the edge of the Sahara Desert (Mali) and is one of the world most productive temporary wetlands. The IND climate is dry most of the year and the wet season usually expands from July to September/October, leading more water availability. The communities surrounding the IND depend mainly on the agriculture and fishing culture. The wetland provides natural resources and livelihoods for over $10 \%$ of Mali's population and $80 \%$ of Mali fish production. The wetland also produces food for about $40 \%$ of the country's cattle[21], [22]
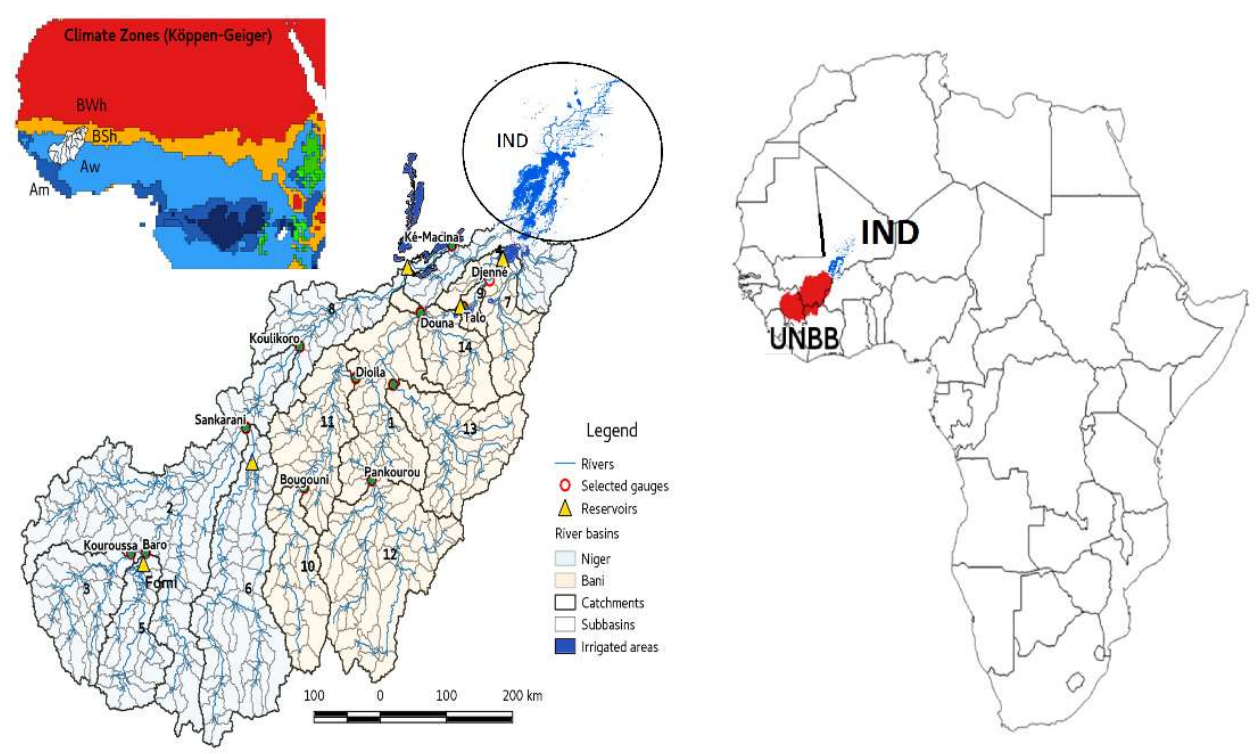

Fig. 3. Map of the case study area of the Upper Niger Basin (UNB) and Inner Niger Delta (IND) with catchments, sub-basins, discharge gauges, reservoirs, irrigated areas, and climate zones (adapted from [23])

The two main factors affecting the hydrological regime in the UNB and the IND are human-made structures, climate variability and climate change. Rainfall in the Sahel is highly variable and the region experiences alternating episodes of droughts and floods. As in all part of the Sahel, the river flows in Mali have drastically decreased in the 1970-2010 period compared to the 1950-1970 period. Decreasing precipitation and depleted groundwater reserves are thought to be the main causes, but dam operation and irrigation are also contributing factors. There are currently 5 major dams in operation in the UNB, and 4 other planned or in development[24]. Among existing reservoirs, the Selingué multipurpose dam, commissioned in 1981, has the largest impact on flows in the watershed. Besides producing hydropower, the dam has the mission to maintain a minimum discharge during the dry season for a large-scale irrigation scheme called Office du Niger (OdN). The OdN is located upstream of the IND and occupies around 100,000ha, for a potentially irrigable area of more than 1,000,000ha. The maximum inundation area shrinked from around $18,000 \mathrm{~km}^{2}$ between 1905 and 1960 to around $10,000 \mathrm{~km}^{2}$ under the combined impacts of climate variability, irrigation withdrawals, and dam operation (Fig.3). 


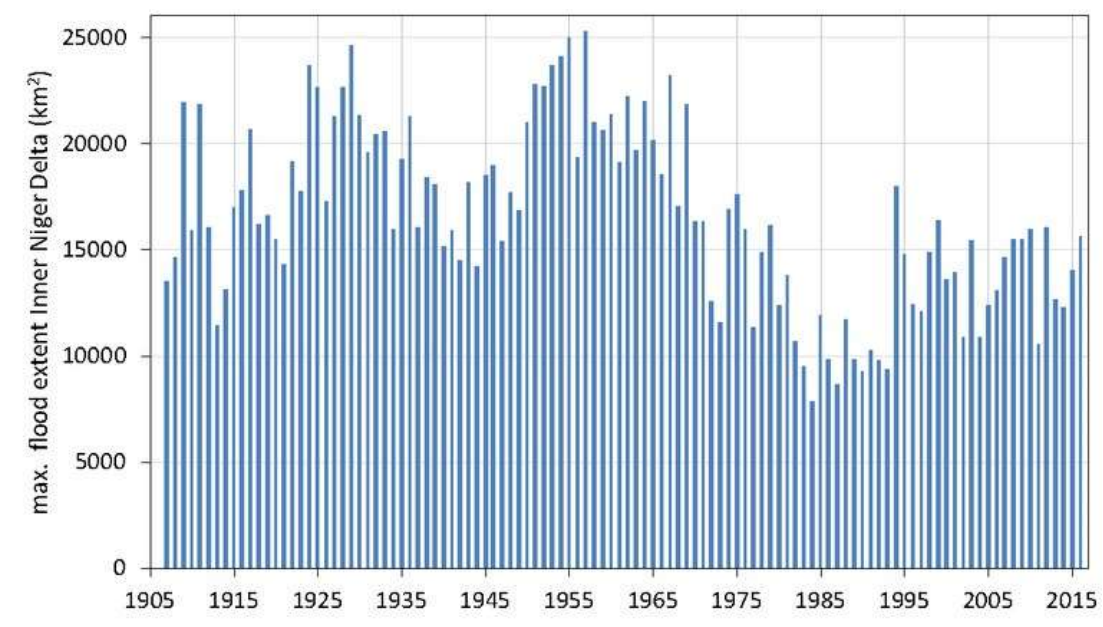

Fig. 4. Flood extent of the Inner Niger Delta[24]

Despite the already visible degradation of ecosystems in the IND, the Malian authorities are eager to expand the irrigated area in the future to maintain food security in the region. Furthermore, the Guinean government is going forward with the planned Fomi/Moussako dam to provide hydropower, with irrigation and flood control, creating even more uncertainty in the future of the IND. At this date, the combined effect of planned and existing dams and irrigation schemes on the flood regime in the IND is largely unknown. This is particularly worrisome as empirical data shows that resource productivity in the IND is highly correlated to the maximum flood extent[25].

\section{IWRM/WE' $F$ nexus initiatives in the UNB and IND}

The IND and UNB are part of the Niger River basin, which is shared by nine countries:Benin, Burkina Faso, Cameroon, Chad, Ivory Coast, Guinea, Mali, Niger, and Nigeria. The Niger Basin Authority (NBA) is an intergovernmental agency tasked with the promotion of the coordinated development of Niger Basin resources in a broad range of sectors: water, energy, agriculture, livestock, fisheries, forestry, mining, transport and communication. The NBA and its partners fully adhere to the concept of IWRM, and the NBA typically coordinates the studies and development of projects that are likely to have transboundary impacts. It collects and centralises hydrometric data throughout the watershed, and has commissioned the development of a water allocation model of the Niger basin using Mike Basin. Based on the model, the NBA has established minimum flow targets at the boundaries of each country. Potential projects are submitted to the NBA, which estimates the potential impacts using the Mike Basin model of the watershed. Unfortunately, the model has several limitations. It does not have a rainfall-runoff module and hence cannot account for climate variability/change; it cannot represent the complex hydrologic behaviour of the IND; it does not have an ecological module; an external firm developed it and the NBA does not have the in-house expertise to update it and represent the current configuration of the watershed. Aware of the concerns about the impacts of FOMI/Moussako, the NBA has recently launcheda study on advanced modelling of ecosystem services in the Inner Niger Delta (IND), which involves the development of a hydrodynamic model and the estimation of ecosystem services in the IND under various development and climate change scenarios, as well as Environmental flow (Eflow) estimation at key locations. Unfortunately, because of the lack of high-resolution elevation data for the IND, the simulated flood extents significantly deviate from observations. 
Furthermore, ecosystem services were estimated using relatively imprecise correlations with water levels such as the one developed in [25] (Figure 5), leading to a huge uncertainty in the results. Therefore, as of today, despite its willingness to implement IWRM in the basin, the NBA does not have the tools and data to state with certainty how ecosystems in the IND will react to climate change and infrastructure development.

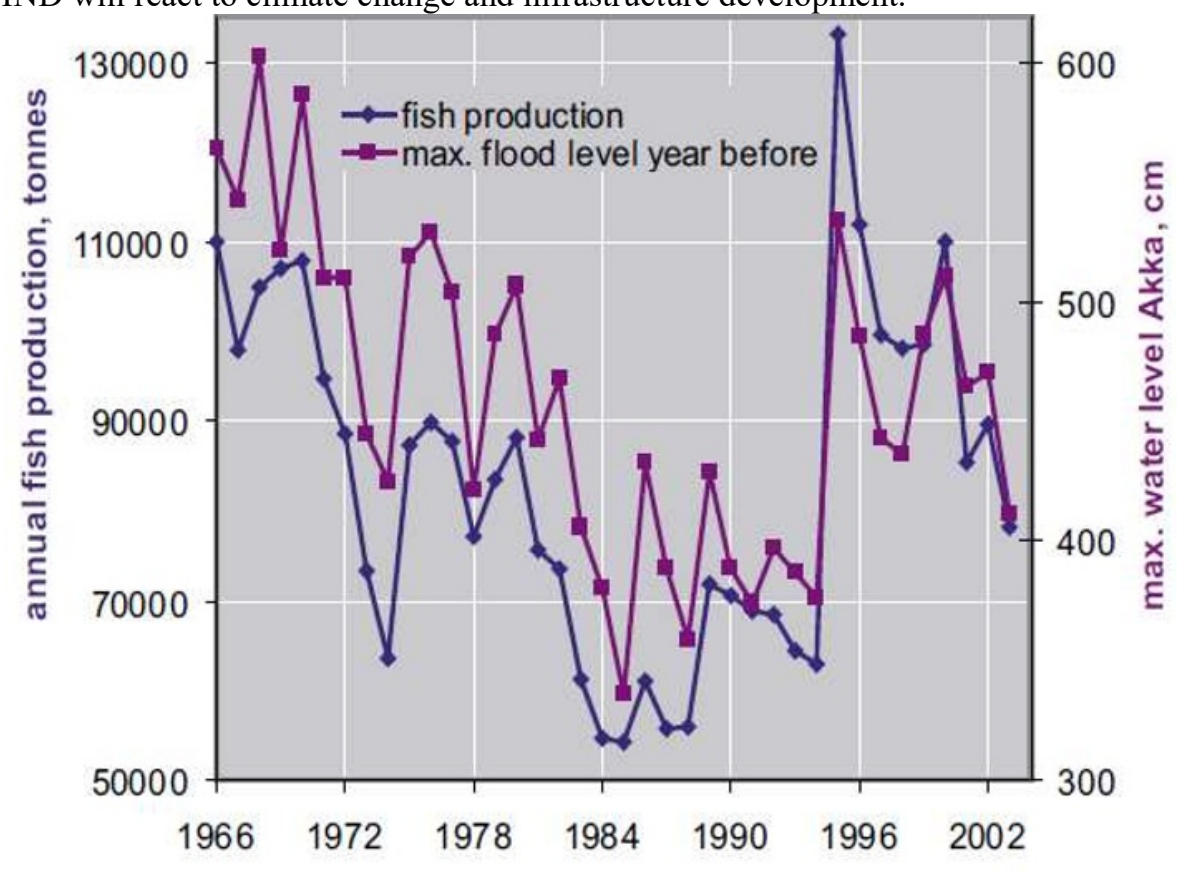

Fig. 5. Fluctuation in annual fish catch in the Inner Delta between 1966 and 2003 compared to the fluctuation in flood level (Akka, cm) in the year before[25]

A good understanding of the physical, environmental and economic system is not sufficient to achieve $\mathrm{WE}^{2} \mathrm{~F}$. A continuous dialogue between stakeholders is fundamental to build public adhesion and political willingness to take decisions that may not align with the interests of individual actors. The EU Nexus Regional Dialogue Programme, funded by the European Union, was initiated to sustainably strengthen the political processes needed at the regional and national levels to meet the increasing demand for water, energy and food. It brings together stakeholders to develop concrete policy recommendations and action plans for future investments, with specific emphasis on multi-sector infrastructure and corresponding capacity development activities. There have been so far five regional dialogue regions: The Middle East and North Africa, America and the Caribbean, Southern Africa, and Central Asia and finally, the Niger Basin. As part of the Niger Basin Nexus Dialogue, the GIZ funded a study aiming to help the NBA use a Nexus angle to screen/prioritize intervention and infrastructure projects in the basin. A conceptual procedure was developed to score interventions and estimate trade-offs, but the lack of adequate data and appropriate modelling tools led to a lot of subjectivity in the assignment of scores, hence in the final prioritization of investments.

The BAMGIRE project was probably the most comprehensive attempt to understand the interlinkages between water, energy and sustainability in the UNB and IND. A continuous dialogue was established with the Malian and Guinean governmental services through a series of workshops dedicated to either two-ways knowledge exchange, capacity building 
or both. In parallel, knowledge products such as ecosystem services (ESS) mapping, hydrological (SWIM: Soil and Water Integrated Model) and hydraulic models were being developed (Figure 6). The ultimate goal was to develop a decision support system, called Decidaid.

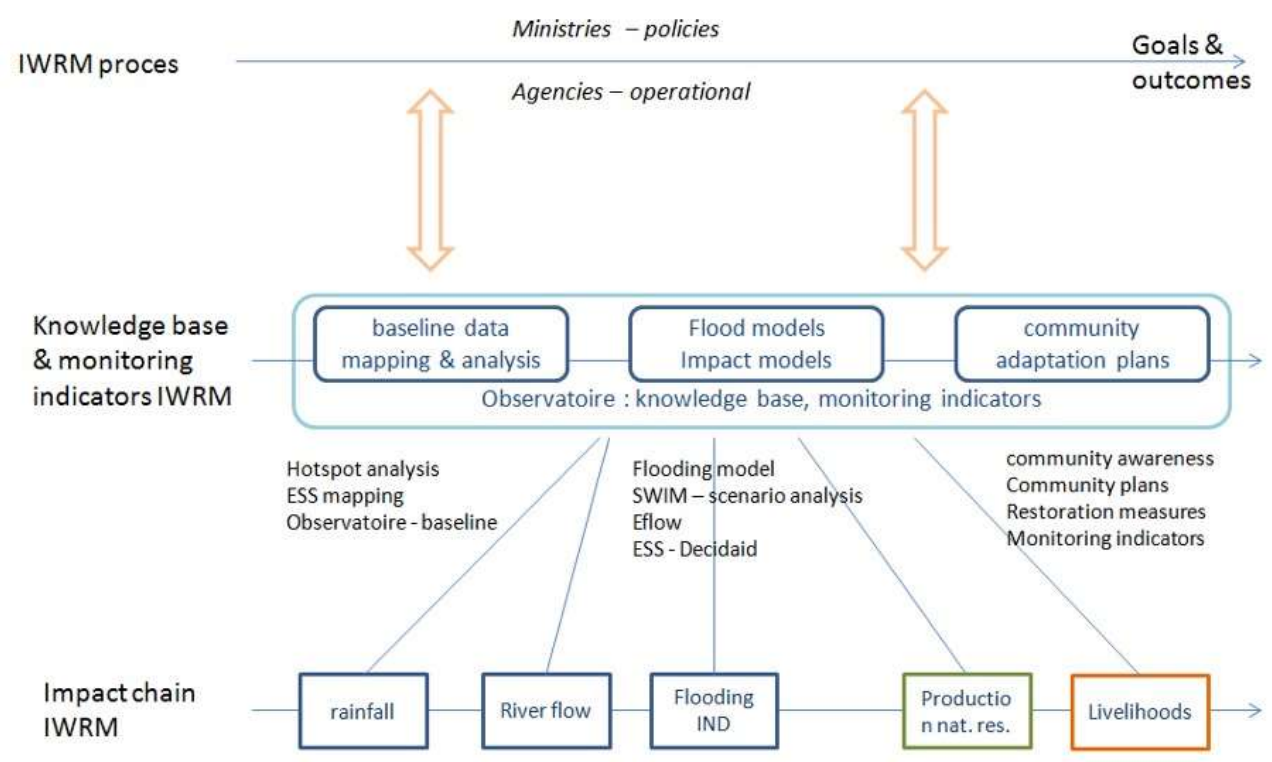

Fig. 6. Knowledge generation process in the BAMGIRE project. ESS

While data availability has been a challenge for all knowledge products generation, the two main challenges were the description of the flood regime in the IND and its links to ecosystem services. Flood model development of the IND is particularly challenging because of its complex network of streams and lakes, its large size, and the lack of precise topographic data. A first model was developed by coupling observed water levels with satellite imagery, before a full hydrodynamic was developed using a topographic data derived from secondary sources. Before the BAMGIRE project, the only available method to estimate ecosystem series in the IND was through oversimplified regressions using water levels at specific stations. These relations do not account for the actual ecological processes and may not hold in situations where the flood regime deviates from what have been observed in the past. A significant amount of resources was invested in developing aconceptual model called PROBFLO that demonstrate the causal risk pathways from identified sources (including anthropogenic and natural activities/events) to stressors (water quality, flow and habitat modifications for example), socio-ecological receptors in multiple habitats to endpoints[26], [27]. The impact pathways in PROBFLO are presented in Figure 7. According to the developers, PROBFLO is flexible enough to use any kind of relationships between drivers and impacts, from conceptual equation to empirical relations, or expert opinion. While the PROBFLO model constitute a significant achievement in the understanding of how climate and water management is likely to affect ecological endpoints, the lack of data to calibrate and validate the model leads to a low credibility in its output. A strong recommendation of the BAMGIRE project is the implementation of a monitoring plan that would allow a better calibration of the model, and an adaptive management plan that would be regularly updated according to new evidence and improvements in the understanding of the system. 


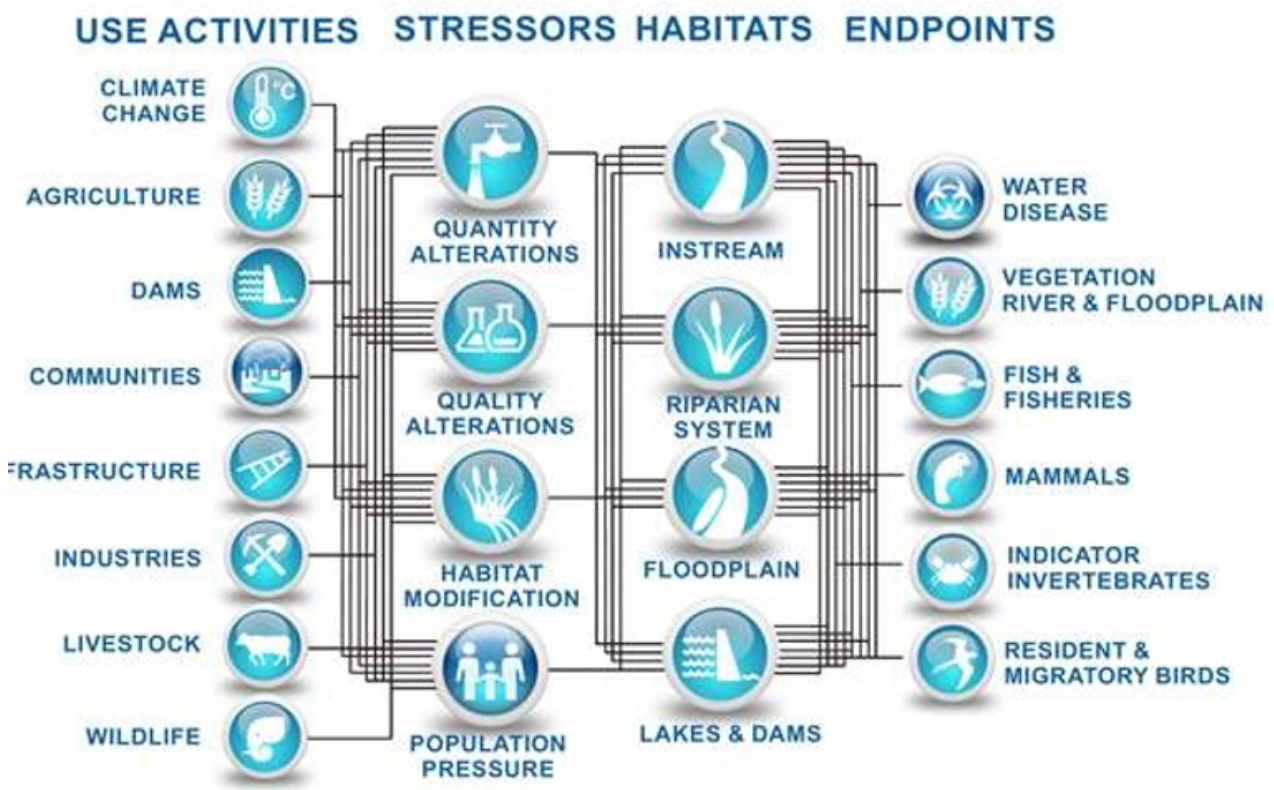

Fig. 7. Impact pathways in the PROBFLO model of the UNB and IND[26], [27]

The authors believe that despite significant progresses made in the BAMGIRE project, our knowledge of linkages between water, food, energy and environmental sustainability is still insufficient to estimate precisely trade-off between sectors. However, the project triggered valuable discussions between scientists of different disciplines, between stakeholders and highlighted the limits of our knowledge of the system, while improving our collective understanding of the challenges related to resources management in the IND and UNB. The project set the stage for more data collection, more tool development and more dialogues among actors. It is unlikely that a full understanding of the system will come anytime soon, but the outputs of the project made Mali and Guinea closer to a common understanding of how their infrastructure and management decisions would affect development objectives across sectors.

\section{Conclusion}

Just like previous holistic approaches to environmental decision making such as IWRM, the WE2F is a powerful tool for framing sustainability issues and foster discussions among stakeholders. It has the advantage over IWRM of (at least in theory) treat all sectors equally. However, there are multiple barriers to its implementation, such as complexity and data availability. It demonstrated that initiatives in the Upper Niger Basin related to WE2F nexus or other similar concepts such as IWRM were successful in stimulating inter stakeholder dialogues and tightening the political will implement a trans-sectorial and transnational management of resources in the watershed. The initiatives also led to significant knowledge generation and data collection, although considerable knowledge gaps remain, especially about flood dynamics in the IND and the relationships between the flood regime and ecosystem services. A full understanding of all interlinkage between sectors may never be possible, but data collection and model development can improve our ability to understand the system and take better decisions. 
The authors thank the Wetlands International and Embassy of the Netherlands, Mali, for funding this research.

\section{References}

[1]United Nations, Department of Economic and Social Affairs, Population Division, World Population Prospects 2019: Highlights., (United Nations, Department of Economic and Social Affairs, New York, USA,2019)

[2]International Resource Panel, Global Resources Outlook 2019: Natural Resources for the Future We Want, (United Nations Environment Programme, Economic Division, Nairobi, Kenya,2019)

[3]United Nations General Assembly, Transforming our World: the 2030 Agenda for Sustainable Development, (United Nations, New York, USA, 2015)

[4]M. Rohlmann, Integrated natural resource management? a question of property institutions?, GeoJournal29, 4, (1993)

[5]B. Douthwaite, J. M. Ekboir, S. J. Twomlow, and J. D. H. Keatinge, The concept of integrated natural resource management (INRM) and its implications for developing evaluation methods., in Natural resource management in agriculture: methods for assessing economic and environmental impacts, B. Shiferaw, H. A. Freeman, and S. M. Swinton, Eds. Wallingford: CABI, (2005)

[6]M. M. Rahaman, O. Varis, Integrated water resources management: evolution, prospects and future challenges, Sustain. Sci. Pract. Policy, 1, 1, pp. 15-21, (2005)

[7]O. Graefe, Integrated Water Resources Management as a New Approach to Water Security, in Eating, Drinking: Surviving, P. Jackson, W. E. L. Spiess, and F. Sultana, Eds. Cham: Springer International Publishing, (2016)

[8]J. Hassing, Unesco, World Water Assessment Programme, Integrated water resources management in action: dialogue paper. Paris: UNESCO, (2009)

[9]J. A. Allan, Virtual Water - the Water, Food, and Trade Nexus. Useful Concept or Misleading Metaphor?, Water Int., 28, 1, pp. 106-113, (2003)

[10]A. Y. Hoekstra, P. Q. Hung, Globalisation of water resources: international virtual water flows in relation to crop trade, Glob. Environ. Change, 15, 1, pp. 45-56 (2005)

[11] T. Oki, S. Kanae, Virtual water trade and world water resources, Water Sci. Technol., 49,7. pp. 203-209, (2004)

[12] A. Y. Hoekstra, A. K. Chapagain, Water footprints of nations: Water use by people as a function of their consumption pattern, Water Resour. Manag., 21, 1, pp 35-48, (2006)

[13] A. Y. Hoekstra, M. M. Mekonnen, The water footprint of humanity, Proc. Natl. Acad. Sci., 109,9, pp. 3232-3237, (2012)

[14] H. Hoff, Understanding the Nexus. Background Paper for the Bonn2011 Conference: TheWater, Energy and Food Security Nexus, Stockholm Environment Institute, (2011)

[15] S. J., McGrane, M., Acuto, F., Artioli, P.-Y., Chen, R., Comber,J., Cottee, G., FarrWharton, N., Green, A., Helfgott, S., Larcom, J. A., McCann, P., O'Reilly, G., Salmoral, M., Scott, L. C., Todman, T., van Gevelt, X., Yan, Scaling the nexus: Towards integrated frameworks for analysing water, energy and food, Geogr. J., 185, 4, pp. 419-431,(2019) 
[16] A. Endo, I. Tsurita, K. Burnett, P. M. Orencio, A review of the current state of research on the water, energy, and food nexus, J. Hydrol. Reg. Stud., 11, (2017)

[17] H. Leck, D. Conway, M. Bradshaw, J. Rees, Tracing the Water-Energy-Food Nexus: Description, Theory and Practice: Tracing the Water-Energy-Food Nexus, Geogr. Compass, 9, 8, (2015)

[18] R. Cairns A. Krzywoszynska, Anatomy of a buzzword: The emergence of 'the water-energy-food nexus' in UK natural resource debates, Environ. Sci. Policy, 64, (2016)

[19] J. Liu , H. Yang, C. Cudennec, A.K. Gain, H. Hoff, R. Lawford, J. Qi, L. de Strasser, P.T. Yillia, C. Zheng, Challenges in operationalizing the water-energyfood nexus, Hydrol. Sci. J., 62, 11, (2017)

[20] S. Fan, The 'nexus' between food, energy and water security, (Crawford School of Public Policy, Canberra, 2014)

[21] S, Liersch, S. Fournet, H. Koch, Assessment of Climate Change and Water Management Impacts on the Water Resources in the Upper Niger and Bani River basins,(Wetlands International, 2018)

[22] Royal Haskoning, Altenburg \& Wymenga, and GID., Etat des lieux du Delta Intérieur, -vers une vision commune de développement, (Ministère de l'environnement et de l'assainissement, République du Mali, 2010).

[23] S, Liersch, S. Fournet, H. Koch, A. G. Djibo, J. Reinhardt, J. Kortlandt, F.V. Weert, O. Seidou, E. Klop, C. Baker, F.F. Hatermann, Water resources planning in the Upper Niger River basin: Are there gaps between water demand and supply?, J. Hydrol. Reg. Stud., 21, (2019).

[24] Observatory of Integrated Water Management in the Upper Niger basin and Inner Niger Delta - English. https://onisdin.info/en (accessed Jun. 28, 2020).

[25] L. Zwarts, P. van Beukering, B. Kone, The Niger, a lifeline: effective water management in the Upper Niger Basin. Lelystad: RIZA - Rijkswaterstaat, (2005)

[26] C. Dickens, G. O'Brien, R. Stassen, N. Eriyagama, M. Kleynhans, K. Rowntree, M. Graham, R.G. Vere, J. MacKenzie, E. Wymega, E. Mapedza, M. Brunet, M. Desai, J. Hean, E-flows for the Upper Niger River and Inner Niger Delta: Synthesis Report, (IWMI, 2019)

[27] C. O’Brien, Gordon, C. Dickens, E. Hines, V. Wepener, R. Stassen, L. Quayle, K. Fouchy, J. MacKenzie, P.M. Graham, W.G. Landis, A regional-scale ecological risk framework for environmental flow evaluations, Hydrol. Earth Syst. Sci., 22, 2, (2018) 